\title{
LOS ROTOS EN LA GUERRA DE OCUPACIÓN DE LA ARAUCANÍA: LA EXCLUSIÓN DEL LLEULLE (1862-1883)*
}

\author{
THE ROTOS IN THE WAR OF OCCUPATION OF ARAUCANÍA: \\ THE EXCLUSION OF THE LLEULLE (1862-1883)
}

\author{
Mathias Órdenes Delgado**
}

\begin{abstract}
La presente monografía tiene por objeto explorar las condiciones de vida que brindó el Estado chileno y sus agentes a los soldados en la Guerra de Ocupación de La Araucanía. Las fuentes muestran que los lleulles se encontraron atrapados bajo estrechas jerarquizaciones sociorraciales que harían difícil escapar de su condición de exclusión social, a pesar de la utilidad que prestaron en la colonización del territorio mapuche.

Palabras claves: Soldados chilenos, exclusión social, Guerra de Ocupación de La Araucanía.
\end{abstract}

This monograph aims to explore living conditions provided to soldiers by the Chilean state and its agents during the War for the Occupation of Araucanía. The so-called lleulles were trapped under rigid social and racial hierarchies that made it difficult to escape social exclusion, despite the role they served for the colonization of the mapuche territory.

Key words: Chilean soldiers, social exclusion, War of Occupation of Araucanía.

\section{Introducción}

En las últimas décadas un número importante de historiadores y antropólogos han contribuido bastante a explicar el llamado "conflicto mapuche", quedando bastante claro lo que significó la Guerra de Ocupación de La Araucanía para el pueblo mapuche. Es innegable que la Guerra modificó sustancialmente el Wallmapu y sus costumbres ancestrales, quedando relegados a la exclusión y subordinación cultural y política, además de la pérdida de vidas y el saqueo de ganados y de la rica platería mapuche ${ }^{1}$.

Sin embargo, los avances han dejado zonas poco exploradas y otras sin explorar. Se encuentra todavía pendiente, por ejemplo, la historia de las mujeres, de los niños y niñas mapuches, muchos de ellos secuestrados, convertidos en mocitos y rehenes de guerra. Más aún, habita en terreno oscuro la historia de los soldados y otros wingka pobres, ya sea quienes vivían de manera precaria en La Frontera antes del conflicto, o quienes llegaron en oleadas en busca de mejor vida, como los vagabundos y aventureros. Todos ellos fácilmente sumaban miles de personas ${ }^{2}$ y en su mayoría entraron al nuevo orden territorial sin el goce de la propiedad privada de las tierras que alguna vez ocuparon o desearon ocupar.
La presente monografía tiene por objeto explorar las condiciones de vida que brindó el Estado y sus agentes a los soldados en la Guerra de Ocupación de La Araucanía. Se sostiene como hipótesis, que los soldados, conocidos en el período como "lleulles" e identificados muchas veces con el término genérico de "rotos", fueron útiles en las exigencias y estrategias "civilizatorias". Sin embargo, siempre mal recompensados terminaron marginados del proyecto de ocupación. Bajo sospecha constante de las autoridades, ocuparon un lugar inferior en la construcción de estrechas jerarquías sociorraciales perfectamente reconocibles a fines del siglo XIX, debajo de los inmigrantes europeos y terratenientes acomodados. Como veremos, los relatos militares e informes de guerra dan la razón a nuestras apreciaciones.

\section{El lugar del roto en la jerarquización sociorracial}

El siglo XIX en muchos aspectos estuvo marcado por los sesgos y estructuras sociorraciales de la era colonial, a lo que se sumaron el cientificismo positivista y el darwinismo social de fines de siglo. Bajo este estrecho marco de relaciones, si se quería asegurar el "bienestar de la nación", se entendía que

\footnotetext{
* Resultado proyecto FONDECYT No 3170158.

** Universidad Católica de Temuco, Departamento de Antropología, Temuco, Chile. Correo electrónico: mathias.ordenes@ gmail.com
} 
las clases populares, consideradas como miembros más bajos de la escala social y moral (peones libres, soldados, carretoneros, labradores y sujetos similares, catalogados todos con el término genérico de "rotos"), debían ser disciplinadas y corregidas por las autoridades, los patrones y la Iglesia católica. Mayor sospecha recaía sobre los rotos que no se mostraban sujetos a algún tipo de autoridad. Por largo tiempo se sostuvo que el peón libre mostraba los vicios de nuestra clase trabajadora, pues "lleva a las haciendas, junto con sus harapos, la semilla de la desmoralización y del crimen" (Grez 2007:173). Así, la comprensión de lo popular correspondía a un sujeto semibárbaro, casi desprovisto de razón y cercano a la ilegalidad (Salazar 2000; Araya 1999). Bajo tal marco discursivo y de ordenamiento social, muchas veces coercitivo, la oligarquía levantó su proyecto hegemónico de construcción de Estado, excluyendo a las clases populares e intentando imprimir sus valores elitistas, en especial, un orden vertical y una moralidad católica.

La Guerra del Pacífico (1879-1884) cambió parcialmente la percepción que la élite chilena tenía de las clases populares. Los rotos se convirtieron en arquetipos de la identidad nacional y en los héroes que habían conquistado para la patria las ricas regiones gracias a su coraje y sacrificio ${ }^{3}$. "A la simple consideración cristiana, se agregaba ahora los sentimientos nacionalistas heridos por la imagen del 'degeneramiento de la raza' que proyectaban la espantosa mortalidad, las condiciones de vida en ranchos y el alcoholismo" (Grez 2007:173).

En 1888, en la plaza Yungay se rindió homenaje a la carne de cañón de la Guerra del Pacífico con el Monumento al Roto Chileno, y el 20 de enero de 1889 se instituyó la celebración del Día del Roto Chileno. Sin embargo, a pesar de estas reivindicaciones simbólicas, la marginalidad del bajo pueblo no cambiaría. El imaginario social del roto chileno, "dotado de patriotismo", constituyó un debate intelectual y político que duraría varias décadas, demostrando con ello que las élites, a pesar de las reivindicaciones simbólicas, miraban a estos sujetos con recelo, con una desconfianza generada por prejuicios y exclusiones que a la larga impedirían a los rotos escapar de la subalternidad (Gutiérrez 2010) 4 .

Las mismas contradicciones recaían en los rotos de la Guerra de Ocupación de La Araucanía, considerando, además, que en su etapa final una parte de los solados de la Guerra del Pacífico fue trasladada a La Araucanía para poner término al proceso. De esta forma, los soldados se encontraron atrapados en una condición dicotómica: como héroes de guerra y, a la vez, como componentes inferiores de jerarquías sociorraciales construidas por la hegemonía oligárquica, donde surgieron fenotipos antropológicos que afectaron duramente a los "cholos" y "mestizos", identificándolos como "semibárbaros", y que pesaron duramente sobre los "valientes soldados". Las mediciones antropométricas cientificistas de la época construyeron un sujeto popular y mestizo sociorracialmente delictual, cuyos rasgos "atávicos" supuestamente determinaban conductas moralmente insanas (León 2016), al mismo tiempo que gran parte de la élite capitaleña los excluyó en el reparto de las tierras del sur, considerándolos como incapaces para la agricultura (Pinto 2003:115-120).

\section{El Ejército chileno en el siglo XIX y la Guerra de Ocupación}

Desde la Colonia y hasta casi terminar el siglo XIX, el Ejército constituyó un cuerpo semiprofesional, formado por un contingente reducido de fuerza permanente, cuyos altos mandos pertenecían a los grupos cerrados de la élite y una cantidad significativamente mayor de soldados civiles (cuerpos cívicos) eran reclutados en momentos de guerra en calidad de personal ocasional, todos ellos de extracción popular (Vargas 2004). En el caso de la Guerra del Pacífico, por ejemplo, 95\% de las fuerzas provenían del mundo civil y solo el 5\% pertenecía al ejército permanente (Méndez 2009:16). En la Ocupación de La Araucanía las cifras eran similares. Un informe muestra que en 1869 el 92\% del Ejército de La Frontera lo componían soldados y clases, estos últimos eran cabos y sargentos. En cuanto a su reglamentación, desde 1839 a 1927 se rigió, con pocas modificaciones, por la Ordenanza General del Ejército y Marina; quedando también afecto el Ejército de La Frontera, lo que implicó sistemas de enganche y reclutamiento similares en ambas guerras. A pesar de la larga trayectoria de la Ordenanza, el Ejército pasaría de la influencia española, heredera de la era colonial, a mezclar rasgos de influencia francesa en el período independentista, para, una vez concluida la Guerra del Pacífico, adoptar decididamente la influencia prusiana, desarrollando así su profesionalización (Puigmal 2005; Rothkegel 2005).

En el sur el conflicto se desarrolló en etapas, definidas tanto por las estrategias militares como 
por los fenómenos bélicos ocurridos al norte de $\mathrm{La}$ Frontera, lejos del territorio mapuche. Una vez confirmado el plan de ocupación de Cornelio Saavedra, entre 1862 y 1868 se avanzó fundando una línea de fuertes y poblados hasta el río Malleco. Esta primera etapa se vería dificultada por la Guerra con España (1864-1866), que disminuiría las fuerzas militares en La Frontera. En 1867-1868 se produce un gran alzamiento indígena cuya derrota abriría una nueva etapa. En 1878 la línea de fuertes avanzó hacia el río Traiguén y se produce la Guerra del Pacífico. La disminución de tropas por el conflicto en el norte, entre otros, provocaría un último alzamiento indígena, en 1881. En ese escenario, para cerrar la ocupación en una última etapa fueron enviadas tropas desde el norte, soldados de la Guerra del Pacífico que terminaron con el alzamiento. Se funda Temuco, en 1881, se establece la línea del Cautín, en 1882, y se ocupa Villarrica, en 1883. De esta forma, aunque la guerra nunca cesó totalmente, experimentó períodos de aumento y disminución, de acentuación y retroceso de la violencia, junto con la derrota mapuche por la pérdida de animales, tierra, cultivos, su rica platería y muchas vidas (Bengoa 2008:205-324).

Es útil advertir que los informes de guerra no siempre informan el total del Ejército y no siempre diferencian entre el personal ocasional y el permanente, ni tampoco entregan suficiente información acerca del número de bajas de uno y otro bando, seguramente con objeto de no producir una sensación alarmista en la prensa, como la ocurrida algunos años (Bengoa 2008:221-222). La revisión de los antecedentes nos permite presentar los siguientes cuadros según etapas señaladas.

\section{Los lleulles de La Frontera: la exclusión}

El Estado envió a "pacificar" La Araucanía no solamente a inexpertos y jóvenes soldados, entre ellos también había bandoleros, expresidiarios y

Tabla 1. Ejército de La Frontera en las primeras etapas.

\begin{tabular}{|c|c|c|c|c|c|}
\hline \multirow{2}{*}{\multicolumn{2}{|c|}{ Primeros años, $1864 *$}} & \multicolumn{4}{|c|}{ Alzamiento General, 1867-1868 } \\
\hline & & \multicolumn{2}{|c|}{ Costa de La Frontera, 1867} & \multicolumn{2}{|c|}{ Línea del Malleco, 1868} \\
\hline Cuerpos & Unid. & Fuertes & Unid. & Fuertes & Unid. \\
\hline Plana Mayor y dos compañías del Buin $1^{\text {a }}$ Línea & 140 & Toltén & 267 & Curaco & 30 \\
\hline \multirow{3}{*}{ Plana Mayor y dos compañías del Buin $3^{\mathrm{a}}$ Línea } & 140 & Queule & 56 & Peralco & 30 \\
\hline & & Collico & 25 & Collipulli & 163 \\
\hline & 400 & Boldo & 20 & Mariluán & 63 \\
\hline \multirow[t]{2}{*}{ Batallón $7^{\circ}$ de Línea } & & Quidico & 149 & Chiguaihue & 195 \\
\hline & & Lebu & 12 & Lolenco & 55 \\
\hline Granaderos a Caballo & 279 & & & Cumcurra & 56 \\
\hline 1 Comp. Artillería & 83 & & & Angol & 392 \\
\hline Total & 1042 & Total & 529 & Total & 984 \\
\hline
\end{tabular}

Tabla 2. Ejército de La Frontera en etapas finales.

\begin{tabular}{|c|c|c|c|}
\hline \multicolumn{2}{|c|}{$\begin{array}{c}\text { Línea del Traiguén, } 1878 \\
\text { Alta y Baja Frontera }\end{array}$} & \multicolumn{2}{|c|}{$\begin{array}{c}\text { Alzamiento General, } \\
1881\end{array}$} \\
\hline Cuerpos & Unid. & Cuerpos & Unid. \\
\hline Alta Frontera & & Batallón Biobío & 410 \\
\hline Batallón Buin $1^{\text {a }}$ de Línea & 302 & Batallón Angol & 592 \\
\hline Batallón $3^{\text {a }}$ de Línea & 300 & Batallón Arauco & 571 \\
\hline Cuerpo Cazadores & 334 & Batallón Ñuble & 602 \\
\hline Reg. Cazadores a Caballo & 121 & Cuerpo Carab. Angol & 180 \\
\hline Reg. Granaderos a Caballo & 230 & & \\
\hline Baja Frontera & & Cuerpo Carab. de La Frontera & 217 \\
\hline Batallón $2^{\circ}$ de Línea & 152 & & \\
\hline Total & 1439 & Total & 2572 \\
\hline
\end{tabular}

*Plazas: Los Ángeles, Nacimiento, Negrete, Mulchén, Arauco, Lebu.

Fuentes: Navarro 2013: 111, 145, 331; Heise, Silva, Claro 1981: 177; ANH, MG 536, Angol, 5 junio 1868, fs. sn. 
veteranos de más de una guerra. Sujetos desposeídos que harían lo posible por obtener algo del despojo, aunque sea su propio alimento. Sujetos con tal grado de exclusión y en general con historias de vida que les dificultaba construir una mejor moralidad, en manos de mandos superiores inescrupulosos, se convertían en un peligroso arsenal de guerra (Parvex 2015:255-302).

$\mathrm{Al}$ igual que en la Guerra del Pacífico, bajo el criterio de "la nación en armas" (convertido en Ley desde la Constitución de 1823; Heise, Reyno, González 1981:86), los soldados que resolverían el destino de La Frontera fueron reclutados mediante sistemas de enganche o a la fuerza ${ }^{5}$. El único requisito para ser enganchados habría sido ser considerados "capaces de tomar armas", por lo que en su mayoría los nuevos movilizados del ejército eran jóvenes de entre 16 y 30 años, según la Ordenanza General, pero, de acuerdo con la discrecionalidad e indolencia de mandos superiores, también se reclutaban a menores de 16 años (Heise, Reyno, González 1981:253). En medio de los temores y las tristes despedidas, el discurso del fervor patrio de las autoridades y la música de la banda militar generaban un ambiente curiosamente festivo, que buscaba provocar resignación transmitiendo la idea de una causa noble (Alderete 2016:9-13) ${ }^{6}$. La prensa colaboró notoriamente en la construcción de ese ideario (Rubilar 2015).

Luego de unas pocas horas de improvisado entrenamiento, de menos de un día y que apenas servía para aprender a cargar un arma y obedecer, de un momento a otro un roto cualquiera pasaba a ser calificado de "lleulle", soldado de menor escalafón, pero de mayor número, que acompañaría al ejército semiprofesional en calidad de carne de cañón (Alderete 2016). Los lleulles dejaban atrás sus rancherías, conscientes que sus familias ya no contarían con sus brazos para traer el pan, o matando de un momento a otro su juventud camino a lo desconocido, olfateando la muerte. Atrás quedaba el eco triste de las madres y esposas, muchas de ellas reclamando a los oficiales algún cuerpo sin vida que nunca les fue devuelto y viendo partir a otro ser querido rumbo, tal vez, a la misma suerte (Alderete 2016:10-13). En menor cantidad junto con ellos eran trasladadas esforzadas mujeres y jóvenes madres que, en ocasiones, con sus hijos componían las familias de los soldados. Este contingente miserable de población civil y militar, con más apariencia de refugiados de guerra que de ejército profesional, era trasladado en largas jornadas a pie, a caballo, en embarcaciones y carretas arrendadas, muy pocas veces en tren, ya sea por su ausencia o por su alto costo.

Una vez en La Frontera, los soldados y sus acompañantes eran instalados en la periferia de las nacientes ciudades, ocupando sitios para la explotación agrícola, lo que servía, en primera instancia, de cerco humano que protegería a las nuevas poblaciones de colonos ${ }^{7}$, emplazadas más cerca de los fuertes. Este control facilitaba también las actividades que implicaban el avance territorial y mantención del ejército, además de procurar el contacto entre rotos e indígenas, que se suponía facilitaría la civilización de estos últimos, así como lo diseñó el coronel Cornelio Saavedra (Navarro

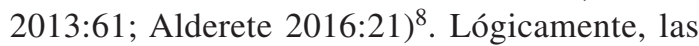
familias de la tropa eran los últimos en encontrar refugio en caso de ataque ${ }^{9}$. La población militar debía abandonar de un momento a otro sus improvisados ranchos, ya sea por algún levantamiento indígena o por la movilización de las tropas ${ }^{10}$. En 1867 el general Basilio Urrutia entrega al ministro de Guerra un informe sobre Angol:

Esta población a principios de 1863 , no contaba con más edificios que el cuartel, siendo en lo demás una aglomeración irregular de miserables ranchos construidos provisionalmente para las familias de las clases y tropa de la guarnición y de un corto número de comerciantes que seguían al Ejército, se acerca hoy por el número de sus habitantes, animados casi todos del mejor espíritu de adelanto, por el número y clase de sus edificios, arreglo de sus calles, etc., al rango de los pueblos más importantes de la provincia. El número de sus habitantes asciende actualmente a 1.520 de los cuales 718 pasan de la edad de quince años y no exceden de cincuenta. Hay 236 casas concluidas de las cuales noventa tienen techo de teja, 144 con techo de paja, dos con maderas, y se construyen actualmente ciento veinte de la primera clase y trece de la segunda (Navarro 2013:127).

El contacto entre soldados y mapuches no siempre se desarrolló en combate, las fuentes muestran un nutrido comercio en torno a los fuertes desde los primeros meses de ocupación, donde el alcohol 
produjo estragos en los indígenas. El comercio en esas condiciones comprendió una de las estrategias de ocupación militar (Navarro 2013:61, 137; Olivares 1939:34-36; Parvex 2015:289).

A cambio de sus servicios, el lleulle malamente recibía lo necesario para su subsistencia. Al comenzar la ocupación contaban con un sueldo mensual de $\$ 9$, que luego subiría a $\$ 11$. Pago superior al de un peón de la zona central ${ }^{11}$. Sin embargo, a ello se descontaban $\$ 4$ por alimentación ("rancho"), más otros descuentos por botas, ropa interior y útiles de aseo. En caso que los soldados no recibieran rancho, contaban con un abono de 10 a 12 centavos diarios. El Fisco solo daba, cada dos años, dos trajes de paño, una manta o capote y una lona que era usada como especie de colchón, "la tabla", como la llamaban (Navarro 2013:215-216). Quienes cumplirían servicio por pocos meses no recibían ropa ni implementos. Es probable que la mayoría de los lleulles nunca los recibiera ${ }^{12}$.

Si por desventura alguno terminaba en el improvisado e insalubre Hospital del Ejército, su remuneración se reducía nuevamente, debiendo cancelar 13,5 centavos diarios y sufrir el riesgo de alguna epidemia (Navarro 2013:215-216). A lo anterior se sumaba el hecho de que un obrero, peón o gañán, solamente podía acceder a jerarquías menores, cabo o sargento, pudiendo, con mucho mérito, llegar hasta suboficial. Un profesional, en cambio, recibía a su ingreso el grado de oficial (Méndez 2009:19).

Hasta después de la Guerra la remuneración no cambió a pesar del aumento del costo de la vida ${ }^{13}$. El cabo Alderete en sus memorias nos cuenta que, por casi dos meses de servicios, en 1881 se repartió "algún dinero: a las clases de a cinco pesos y a los soldados de a tres, para comprar algunas bagatelas". La chicha de manzana y algún otro licor barato terminaron cobrando gran parte del pago por haber puesto sus vidas en prenda (2016:83). Asimismo, una carta al Ministro de Guerra indica que en 1887 se entregaban a la tropa los mismos 10 centavos de rancho que en 1862 y " 15 a los jefes de las fuerzas"14. En dicho período los sueldos y jubilaciones de los soldados no se modificaron en lo sustancial de la Ordenanza General de 1839, ni de la Ley de Sueldos, dictada pocos años después, en 1845. Bajo esas condiciones, los peones eran mejor remunerados en las minas del carbón que en el Ejército ${ }^{15}$. A pesar de ello, la sola queja o "las murmuraciones que puedan alterar el orden y la disciplina del personal", constituían una falta a la Ordenanza que podía ser sancionada, pues, "Todo militar se manifestará siempre conforme con el sueldo que goza y empleo que ejerce" (Título XXXII, Artículo $1^{\circ}$ ).

Cuando los soldados salían de los fuertes, ya sea para trabajar en obras públicas o del Ejército, o para adentrarse en tierra mapuche, generalmente no contaban con equipaje ni tiendas y solo en algunas ocasiones recibían el mentado rancho: raciones de charqui de equino, una buena porción de grasa $\mathrm{y}$, en el mejor de los casos, algo de harina y unas cuantas "galletas" (un tipo de pan, generalmente sin levadura). De esta forma, habitualmente se confiaba en la ayuda de los indios amigos y en todo lo que se pudiera saquear del enemigo (Leighton 2013:33; Navarro 2013:215; Alderete 2016:23). Así, la necesidad alimentaria de la tropa se convertiría en uno de los motivos de disminución del ganado mapuche. Respecto de los pertrechos de combate, no es nuestro objetivo extendernos, solo diremos que cada soldado generalmente recibía entre 40 y 50 tiros, que de nada servían cuando la lluvia mojaba los cartuchos (Alderete 2016:17) ${ }^{16}$. Como sea, las necesidades diarias nutrían a un mercado cautivo

Tabla 3. Sueldos mensuales de la tropa.

\begin{tabular}{|c|c|c|c|}
\hline \multicolumn{2}{|c|}{$\begin{array}{c}\text { Ordenanza General del Ejército y Marina } \\
\text { (1839) }\end{array}$} & \multicolumn{2}{|l|}{$\begin{array}{l}\text { Ley de Sueldos } \\
\quad(1845)\end{array}$} \\
\hline Sargento $1^{\circ}$ y Tambor Mayor & $\$ 12$ & $\begin{array}{l}\text { Sargento } 1^{\circ} \\
\text { Sargento } 2^{\circ}\end{array}$ & $\begin{array}{l}\$ 15 \\
\$ 13\end{array}$ \\
\hline Sargento $2^{\circ}$ & $\$ 10$ & Cadete & $\$ 13$ \\
\hline Cadete & $\$ 10$ & Cabo $1^{\circ}$ & $\$ 11$ \\
\hline Cabo $1^{\circ}$ y $2^{\circ}$ & $\$ 8$ & Cabo $2^{\circ}$ & $\$ 10$ \\
\hline Soldado, Tambor, Pito o Corneta & $\$ 6$ & Soldado, Tambor, Pito o Corneta & $\$ 8$ \\
\hline
\end{tabular}

Fuentes: Heise, Reyno, González 1981:263; Heise, Silva, Claro 1981:39. 
que enriquecía a comerciantes como el afamado José Manuel Bunster, que vieron junto con el avance de La Frontera un porvenir que nunca alcanzaron en otros lugares (Ferrando 2012:537-543; Navarro 2013:397).

Entre las actividades más importantes se encontraban las obras de infraestructura y comunicación. En 1877 se organizó el Batallón de Línea de Zapadores, incorporando en este al antiguo $7^{\circ}$ de Línea: cuerpo especial que serviría a la formación mixta de soldados y operarios, constructores de obras de ingeniería y carpintería en general ${ }^{17}$. Una circular de la Inspección General del Ejército ordenó que todos los cuerpos de La Frontera seleccionaran a sus carpinteros, herreros y demás individuos de tropa que contaran con algún oficio para que pasaran a Zapadores (Navarro 2013:302). En manos del Batallón quedó gran parte de la construcción de caminos, puentes, canales de regadío, edificios militares y públicos de los primeros años de la ocupación militar.

El trabajo y capacidad productiva de los Zapadores, tan encomiados por el sargento mayor de Artillería, Ambrosio Letelier, en su informe al ministro de Guerra (1877) y recientemente por Sergio Villalobos (2013:17 y 18), muestran las habilidades de los rotos para el aprendizaje de oficios, cuestión que contradecía la creencia de la oligarquía chilena al estimar al bajo pueblo como "estorbo" a la educación y el progreso. Sin duda, el Cuerpo de Zapadores constituyó la mano de obra más barata y mejor calificada con que contaron el Estado y los colonos en su proyecto de "civilización" y explotación de La Araucanía ${ }^{18}$.

Como era de esperar, en varias ocasiones los mandos militares lucraron e hicieron uso privado de la mano de obra a su cargo y de las mujeres que la acompañaban. Cometiendo delitos y cargando sobre los hombros de la población militar una explotación abusiva, se destinaron soldados al trabajo agrícola de particulares ${ }^{19}$ y fueron obligados a construir viviendas de mandos superiores, ocupando, incluso, materiales del $\mathrm{Fisco}^{20}$. Asimismo, se presentaron casos gravísimos de hurto y descuentos arbitrarios de remuneraciones de soldados; como el caso del teniente de la Brigada Cívica Movilizada N ${ }^{\circ} 22$, que fue condenado por la malversación de \$617,63, cifra importante para la época ${ }^{21}$. Lo mismo ocurrió con el teniente de la Brigada de Artillería Movilizada $\mathrm{N}^{\circ} 2$, cuya cifra no pagada a la tropa no manejamos ${ }^{22}$. Por estos hechos, periódicamente la prensa se encargó de elevar denuncias públicas ${ }^{23}$.
Otra de las dificultades enfrentadas por el lleulle fue el cobro de sus miserables remuneraciones. Malcomidos y al acecho de lo que pudiesen saquear para el sustento básico, no les quedaba más que recorrer grandes distancias para elevar sus reclamos. En una carta enviada al ministro, el 20 de mayo de 1881, desde la Comandancia General de Armas de Puerto Montt, se indica:

Se han presentado (...) muchos de los soldados que pertenecieron a las campañas movilizadas 'Llanquihue' i que fueron enrolados en el Batallón Bio-Bio, exponiendo que ni ellos ni ninguno de los trescientos hombres que pasaron al 'Bio-Bio' han sido ajustados de los sueldos correspondientes a enero del presente año. Algunos han asegurado también que han dejado de recibir los sueldos de febrero i marzo.

(...) han agregado también que no se les dio para transportarse a esta provincia dinero ni pasaje, i que se han visto forzados a hacer la travesía desde Arauco a Llanquihue, a pié sin recurso de ningún género ${ }^{24}$.

El problema del atraso en los sueldos fue tan recurrente que dificultaba incluso el avance de la línea de frontera ${ }^{25}$. Gregorio Urrutia escribía al Ministro, el 18 de noviembre de 1882, poco antes de la partida a Villarrica:

(...) creo de mi deber hacer presente a VS. la necesidad de que los Cuerpos de que dicho Ejército se compone sean pagados, si no ya en los puntos en que están sus Planas Mayores, a lo menos en Temuco, que es el más central. Esto facilitará el oportuno pago de las tropas, evitará pérdidas que más de una vez han ocurrido a los habilitados, casi siempre en perjuicio de los intereses fiscales ${ }^{26}$.

A lo anterior se sumaban la escasez y carestía de los alimentos, las malas condiciones de las viviendas, cuarteles, galpones y hospitales donde alojaban cuando tenían la "fortuna" de pernoctar bajo techo, que hacían la vida muy dura, más aún en los helados y lluviosos inviernos. La tropa vivía en condiciones tan miserables que la deserción se convirtió en un problema incontrolable ${ }^{27}$. Así enfatizó estos problemas al ministro Basilio Urrutia en 1872: 
Personalmente he tenido ocasión de convencerme del mal estado i penalidades a que esa tropa está sujeta a consecuencia de la carestía i escases de los artículos de consumo, como así mismo de la carencia de forraje para sus caballos. El soldado invierte ahi la mayor parte de su sueldo en obtener un alimento insuficiente para su necesidad, i el resto distribuido a sus familiares, que acá han permanecido, lo deja sin recurso ninguno i lo coloca en una situación harto difícil, de la que como resultado necesario, no falta el ejemplo de la deserción ${ }^{28}$.

En una curiosa carta dirigida al ministro se solicita que el Ejército siga administrando parte de la remuneración de la tropa con objeto de evitar deserciones, ya que se entendía que el sueldo no alcanzaba siquiera para comida. Se pedía

seguir descontando al soldado como se ha hecho hasta ahora, cinco pesos para suministrarlos oportunamente como está reglamentado por fracciones, para su sustento i lavado de ropa, que no haciéndolo así sucederá que muchos, poco después de pagados, no tendrán con que sudvenir a su alimento, circunstancia que hará más frecuente la deserción ${ }^{29}$.

El lleulle que desertaba prácticamente no tenía alternativas para escapar de una vida miserable, por eso muchos siguieron el camino más fácil: el vagabundaje y el bandolerismo, bajo el riesgo de terminar sus vidas en medio de alguna tropelía o bajo la ley marcial. Otros, en cambio, buscaron suerte en los fundos, explotaron tierras fiscales, trabajaron como carrilanos, habitaron en comunidades mapuches o se aventuraron a buscar mejor vida en Argentina y en zonas australes. Con seguridad, la acción delictual no fue la única vía de escape, pero sí la que obviamente más preocupó a las autoridades.

De esta forma, no compartimos la tesis que sostiene que la única alternativa de los veteranos de guerra fue caer en un círculo de violencia estructural prácticamente insalvable, donde la única respuesta posible frente a la marginalidad y desamparo estatal, fueron los actos delictuales como el bandolerismo (Pinto 1989; León 2005). Si bien el bandolerismo mantuvo preocupadas a las autoridades durante un par de décadas, los exsoldados y otros excluidos buscaron diversas alternativas para ganarse la vida. Las cifras de exsoldados superan con holgura a los bandoleros. Asimismo, un trabajo de M. León (2001) muestra que la delincuencia y el bandolerismo en La Araucanía, no obstante sus particularidades, no superaban a los de la zona central.

Los jubilados del Ejército no corrían una surte significativamente mejor que los prófugos, la situación fue la misma que para los veteranos de la Guerra del Pacífico. Así, por ejemplo, un cabo acogido a retiro por sufrir mutilación en La Frontera recibía una pensión de entre $\$ 4$ y $\$ 6^{30}$, lo mismo que en la Guerra del Pacífico. Un estudio señala: "Los sueldos por este concepto eran tan exiguos, que no alcanzaba para dar satisfacción a las necesidades más apremiantes" (Rodríguez 1984:57).

La mayoría no recibió siquiera una porción de tierra como compensación. El ministro de Guerra y posterior Agente General de Colonización, Isidoro Errázuriz, consideraba a los rotos de manera tan baja que nunca quiso que se convirtieran en colonos. Para él los rotos eran una "masa flotante, sin propiedad y sin techo, sin familia y sin ahorro, sin más solaz que la borrachera y sin más ley que el puñal". Sostenía que la convivencia con este tipo de gente "no convenía siquiera al indio",

Con el chileno -cultivador en pequeño, traficante en animales y licores, desertor o prófugo y frecuentemente malhechor- ha vivido con el indio, de mucho tiempo atrás, en grande intimidad. El chileno ha sido huésped favorito del cacique, y ha tenido permiso para construir su mal rancho de paja a inmediaciones de la ruca (...). Pero no bien se consumó la ocupación chilena y el sometimiento de los indígenas, cuando comenzó a experimentarse un cambio muy desagradable para el indio. De huésped discreto y útil, el chileno se convirtió en entrometido, altanero, ocioso, bebedor y tirano. Desapareció la abeja y quedó el zángano, armado, por desgracia, con el aguijón de aquella (Errázuriz 2014: 179).

Las memorias de Leandro Navarro muestran que en solo una ocasión el ministro Federico Errázuriz ordena al comandante en jefe la entrega de tierras a militares, para ello no se emitió ningún decreto. Esto fue dispuesto para la zona costera de Arauco: 
Usted procurará adquirir todos aquellos terrenos de indígenas que están más inmediatos a las plazas militares (...) y una parte de ellos se destinará a los primeros cien pobladores que quieran avecindarse en aquellas localidades, dándoles un sitio en el pueblo y una hijuela de diez cuadras en el campo. Esta misma gracia se puede hacer a los soldados del Ejército que deseen retirarse del servicio (...). A los demás individuos del Ejército que tengan interés en avecindarse se les puede ceder hijuelas en los términos siguientes:

\section{A los Jefes de Cuerpos. 200 cuadras Los Sargentos Mayores. 150 cuadras Los Capitanes. $\quad 100$ cuadras A los demás Oficiales subalternos. $\quad 50$ cuadras Los Sargentos y Cabos. 20 cuadras} (Navarro 2013:140).

El sargento primero Juan Bautista Olivares cuanta que terminó sus días muy pobre luego de convertirse en veterano de las guerras del Pacífico y Ocupación de La Araucanía. De edad avanzada solicitó un terreno que había sido entregado a su esposa mapuche ya fallecida, 60 hectáreas que sirvieron a sus hijos y 24 nietos, todos casados y con familia (1939:47-48). También cuenta de un soldado que debió "matricularse como indígena sin serlo, por los caciques de la reserva de Nacuncheo dándole estos un pedazo de terreno reconocido ya por el Gobierno" (30).

Aquellos que recibieron sitios o unas cuantas hectáreas no tuvieron los recursos para mantener la pequeña propiedad siquiera por un par de décadas, a ello se sumaron las leyes de colonización y la falta de regulación de la propiedad, que terminaron desplazando a soldados y ocupantes nacionales, siendo absorbidas sus tierras por fundos y grandes hijuelas, como indicó, en 1912, Nicolás Palacios en el Informe de la Comisión Parlamentaria de Colonización.

De esta forma, los veteranos del Ejército de La Frontera, muchos de ellos mutilados, al igual que en la Guerra del Pacífico, encontraron grandes dificultades para reinsertarse en la sociedad y ser compensados por sus servicios a la patria. Lo mismo que sus viudas y huérfanos. A pesar que la Ordenanza General disponía de un régimen de pagos y compensaciones, sufrieron largas tramitaciones para alcanzar montepíos vergonzosos (Rodríguez 1984; Sater 1986; Grez 1997:566; Parvex 2015:278-280).

\section{Conclusiones}

El roto ocupó un lugar marginal en la Guerra de Ocupación y fue dejado a su suerte, las autoridades y quienes perseguirían con rigor la deserción y el bandolerismo, incluyeron de manera subordinada a esa "masa flotante" en el proyecto "civilizatorio", sin prevenir su suerte. Los lleulles y una gran cantidad de población popular se encontraron a la deriva buscando arraigo. La Guerra de Ocupación nos muestra así zonas grises que valen la pena explorar, con ganadores y perdedores, entre los segundos, se encontraron mapuches y chilenos pobres. De esta forma, el Estado y sus agentes fueron construyendo una Araucanía profunda y compleja, llena de tensiones, olvidos y exclusiones.

En cuanto al trato que los soldados recibieron del Ejército Patriota, es posible encontrar similitudes entre la Guerra del Pacífico y la Ocupación de La Araucanía. La exaltación simbólica del roto como ícono de la nacionalidad no se reflejó en una reivindicación moral ni económica de su condición social. Las glorias del Ejército arrastran así grandes contradicciones. El mismo sujeto que fue exaltado, también era muchas veces considerado inferior, incapaz de trabajar y hacer productiva la tierra. Cuando se pensó en ocupar La Araucanía, la mayoría de los ideólogos desestimaron al roto, considerándolo inferior al inmigrante europeo. Representa un desafío explicar si en tal construcción sociorracial, las autoridades dejaron al roto por debajo, incluso, de los mismos mapuches, a quienes decidieron dejarlos con un poco de tierra.

\section{Agradecimientos}

Agradezco a mis colegas del Departamento de Antropología de la Universidad Católica de Temuco, por su buena acogida. 


\section{Referencias Citadas}

Alderete, José del C.

2016 [1934] Apuntes Históricos. Sublevación de La Araucanía en 1881. Temuco, Cagtén.

Anónimo

2013 [1863] "De la última campaña y repoblación de Angol, en la Araucanía, por el Ejército de Operaciones de ultra Bio-Bío, bajo la dirección del teniente coronel y comandante en jefe, intendente de la provincia de Arauco D. Cornelio Saavedra", en Villalobos, Sergio, Incorporación de La Araucanía. Relatos militares. 1822-1883. Santiago, Catalonia, pp. 147-170.

Araya, Alejandra

1999 Ociosos, vagabundos y malentretenidos en el Chile colonial. Santiago, Dibam.

Bengoa, José

2000 Historia del pueblo mapuche (siglos XIX y XX). Santiago, Lom.

Cid, Gabriel

2009 "Un icono funcional: la invención del roto como símbolo nacional, 1870-1888", en Cid, G. y San Francisco, A. (eds.), Nación y nacionalismo en Chile. Siglo XIX. Ediciones del Centro de Estudios Bicentenario, pp. 221-254.

Díaz, José; Lüders, Rolf; Wagner, Gert

1998 "Economía Chilena 1810-1995: Evolución Cuantitativa del Producto Total y Sectorial", en Instituto de Economía de la Pontificia Universidad Católica de Chile, documento de trabajo $N^{\circ} 186$. Santiago, Universidad Católica de Chile.

Ferrando, Ricardo

2012 Y asínació La Frontera... Conquista, Guerra, Ocupación, Pacificación 1550-1900. Temuco, Ediciones UC Temuco.

Grez, Sergio

2007 De la regeneración del pueblo a la huelga general: génesis y evolución histórica del movimiento popular en Chile (1810-1890). Santiago, Ril editores.

Gutiérrez, Horacio

2010 "Exaltación del mestizo: La exaltación del roto chileno", en Universum, Universidad de Talca, vol. 25, № 1 , pp. 122-139.

Heise, Julio; Reyno, Manuel; González, Edmundo 1981 Historia del Ejército de Chile. Tomo III, El Ejército y la organización de la república (1817-1840). Santiago, Estado Mayor General del Ejército.

Heise, Julio; Silva, Osvaldo; Claro, Regina

1981 Historia del Ejército de Chile. Tomo IV, Consolidación del profesionalismo militar, fin de la Guerra de Arauco, 1840-1883. Santiago, Estado Mayor General del Ejército.

Errázuriz, Isidoro

2014 [1892] "Tres razas. Informe de la colonización de Malleco y Cautín, 1887”, en Jorge Pinto e Iván Inostroza Expansión capitalista y economía mapuche: 1680-1930. Temuco, Universidad de La Frontera, pp. 129-275.

Leighton, Thomas

2013 [1826] "Diario de la expedición militar al territorio indio. 1822", en Villalobos, Sergio, Incorporación de La Araucanía. Relatos militares. 1822-1883. Santiago, Catalonia, pp. 31-48.

León, Leonardo

2005 Araucanía: La Violencia Mestiza y el Mito de la Pacificación, 1880-1900. Santiago, Editorial ARCIS.
León, Marco

2001 "Criminalidad y prisión en La Araucanía. 1852-1911”, en Revista de Historia Indígena, Santiago, Universidad de Chile, $N^{\circ}$ 5, pp. 135-160.

León, Marco

2016 Construyendo un sujeto criminal. Criminología, criminalidad y sociedad en Chile. Siglos XIX y XX. Santiago, Lom.

Méndez, Carlos

2009 Héroes del silencio. Los veteranos de la Guerra del Pacífico. Santiago, Centro de Estudios Bicentenario.

Navarro, Leandro

2013 [1909] Crónica militar de la conquista y pacificación de La Araucanía. Desde 1859 hasta su completa incorporación al territorio nacional. Santiago, Pehuén.

Olivares, Juan B.

1939 La pacificación Araucana (1876-1884): relación histórica de la pacificación de la Araucanía de Malleco hasta Cautín, relatada por don Juan Bautista Olivares Ferreira. Padre Las Casas, Imp. San Francisco.

Parvex, Guillermo

2015 Un veterano de tres guerras. Recuerdos de José Miguel Varela. Santiago, Academia de Escuela Militar.

Pinto, Jorge

1989 "El bandolerismo en La Frontera. 1880-1920. Una aproximación al tema", en Villalobos, Sergio y otros, Araucanía. Temas de historia fronteriza. Temuco, Universidad de La Frontera.

Pinto, Jorge

2003 La formación del Estado y la nación, y el pueblo mapuche. De la Inclusión a la Exclusión. Santiago, CIDBA.

Puigmal, Patrick

2005 "Influencia francesa durante las guerras de la independencia Chile: de lo militar a lo político", en Departamento de Historia Militar. Segunda Jornada de Historia Militar, Siglos XIX y XX. Santiago, CESIM, pp. 17-26.

Riveros, Luis

1987 "Evolución de los precios en el siglo XIX", en Estudios Públicos, CEP, № 27, pp. 257-292.

Rodríguez, Sergio

1984 La problemática del soldado durante la Guerra del Pacífico. Santiago, Colección Biblioteca Militar.

Rothkegel, Luis

2005 "Período de transición del Ejército de Chile (1885-1890)", en Departamento de Historia Militar. Segunda Jornada de Historia Militar, Siglos XIX y XX. Santiago, CESIM, pp. 45-60.

Rubilar, Mauricio

2015 "Prensa e imaginario nacional: la misión social de los actores subalternos regionales durante la Guerra del Pacífico", en Diálogo Andino, N $^{\circ} 48$, pp. 41-53.

Salazar, Gabriel

1985 Labradores, peones y proletarios: formación y crisis de la sociedad popular chilena del siglo XIX. Santiago, Lom.

Sater William

1986 Chile and the War of the Pacific. USA, University of Nebraska Press.

Subercaseaux, Francisco

2013 [1888] "Memorias de la campaña a Villarrica 1882-1883", en Villalobos, Sergio, Incorporación de La Araucanía. Relatos militares. 1822-1883. Santiago, Catalonia, 285-351. 
Vargas, Juan Eduardo

2004 "Composición social del Ejército del Reino de Chile", en Departamento de Historia Militar. Primera Jornada de Historia Militar, Siglos XVII-XIX. Santiago, CESIM, pp. 89-94. Véliz, Claudio

20015 "Bajo la tienda (1958). La representación subalterna del 'roto' como fundamento de nacionalidad para el siglo XX chileno", en Diálogo Andino, № 48, pp. 7-17.
Villalobos, Sergio

2013 Incorporación de La Araucanía. Relatos militares. 1822-1883. Santiago, Catalonia.

\section{Archivo}

Archivo Nacional Histórico (ANH), Ministerio de Guerra (MG), Volúmenes: 486; 536; 602; 644; 1045.

\section{Notas}

1 Ver, por ejemplo: Bengoa (2008), Pinto (2003) y Mariman y otros (2006).

2 Hacia 1850 unos 13.000 chilenos se encontraban junto a las tribus desde el río Biobío hasta el río Malleco y unos 14.000 en Arauco, siendo menos numerosa la población indígena en esas localidades (2.800 y 1.600 , respectivamente; Villalobos 2013:10). Subercaseaux, recordando las observaciones del coronel Urrutia, cifra entre 50.000 y 60.000 los habitantes de toda La Araucanía (2013:260). Los Censos de población del siglo XIX y comienzos del XX están viciados de subregistro y cifras negras, por lo que su consideración es discutible, tomando en cuenta además que no diferencian claramente entre mapuche y no mapuche en el caso de la población rural. El Censo de 1868 registró una población de 80.000 personas en la región (Bengoa 2008:252).

3 Un trabajo bien conocido al respecto es el de Gabriel Cid (2009).

$4 \quad$ Un ejemplo de este debate lo constituye el texto de Daniel Riquelme, Bajo la Tienda, cuyo discurso épico respecto de la nacionalidad chilena instala, con un fin pedagógico, la figura del "roto" como una subalternidad masculina simbólica. Apropiando los valores de coraje, audacia y lealtad, Riquelme releva la imagen del roto utilizando el escenario de la Guerra del Pacífico, pero sin modificar la condición de subalternidad (Veliz 2015).

5 Respecto de la Guerra del Pacífico, es bien sabido que las reclutas de soldados se realizaron mediante acuartelamientos forzosos, incluso con evidentes medidas de engaño, en muchos casos con promesas de dineros y estímulos que jamás fueron entregados (Sater 1986).

6 Acerca del momento del reclutamiento, hemos observado características idénticas en ambas guerras. Respecto de la del Pacífico, ver, McEvoy 2013:252-263.

7 Las fuentes no indican de manera explícita que la población militar servía de cerco humano, sin embargo, su emplazamiento en un contexto de guerra permite llegar a esta conclusión obvia.

8 Un militar presente en la ocupación de Angol señala: "Parte de la tropa se empleaba en disponer sus cargas y el resto en trasladar sus familias, equipajes, pertrechos de guerra y demás aprestos. Las mujeres, conduciendo sus pequeños atavíos confundidos entre la multitud de carretas que cruzaban en distintas direcciones, se disputaban el paso (...). Las familias de la tropa componen una población separada, formando en su centro una callecita que viene a terminar en el pueblo, y aunque sus ranchos han sido provisionalmente aderezados, su aspecto no deja de representar una vista un tanto agradable" (2013:165). Otra fuente señala respecto de la campaña de Villarrica: “como completando la entusiasta hueste, que llevaba la nobilísima misión de pacificar aquellos salvajes campos, seguía un numeroso convoy de carretas sobre muchas de las cuales veíanse unas 150 mujeres, siete de las cuales tuvieron feliz aunque prematuros alumbramientos bajo las bóvedas de frescas hojas que ofrecíanles las majestuosas montañas de altos y robustos robles" (Subercaseaux 2013:293).

9 ANH, MG 536, Los Ángeles, 21 marzo 1866, fs. 277-280 vta.

10 ANH, MG 536, Los Ángeles, 21 marzo 1866, fs. 277-280 vta.; Santiago, 8 mayo 1868, fs. 411-415.

11 En 1865 un peón urbano recibía en Santiago sobre \$ 7 mensuales, mientras que uno rural bordeaba los $\$ 5$, lo mismo que un carrilano en Valparaíso (Díaz, Lüders y Wagner 1998: Cuadro 3.2, 48).

12 Alderete nos cuenta en sus memorias: "entregué al Sto. $1^{\circ}$ del piquete, la nómina de los hombres que lo componían y la relación de sargentos y cabos. Cuando leyó mi nombre dio frente a retaguardia, abrió su caja-baúl y sacando de él un kepí me dijo: 'Mi cabo, cambie su 'tomgoy' por esta gorrita'. Orgulloso me encontré al verme con una prenda del ejército. Claro, ya era cabo $1^{\circ}$ ". El relator de estos hechos también indica no haber recibido ropa del Ejército, ni siquiera "una mala manta para cubierta" (2016:14 y 18).

13 El costo de la vida subió considerablemente durante el siglo XIX. El índice general de alimentos, vestuario y calzado aumentó el doble en 25 años, de 108,09\%, en 1863 , a 210,05\%, en 1888 (base 1853=100) (Riveros 1987: Cuadro 2, 269).

14 ANH, MG 1536, Temuco, 10 junio 1887, fs. sn.

15 Debido al bloqueo de los puertos en la guerra con España, se organizaron en Lota los Batallones Cívicos. Al concluir el peligro los soldados elevaron peticiones para ser liberados del ejército y volver a sus labores en las minas. Ello indica que buscaban mejores alternativas económicas que lo que ofrecía la Guardia Cívica (ANH, MG 536, Lota, 5 febrero 1866 , fs. 262, vta.).

16 "El armamento que usaba nuestra Infantería era el fulminante, de cargar por la boca, ánima lisa; después vino el reformado sistema francés Minié, rayado. El batallón $\mathrm{N}^{\circ} 5$ de Línea cuando llegó a la frontera en 1859, aún traía todavía fusiles de chispa. El rifle de precisión y retrocarga Comblain $\mathrm{N}^{\circ} 2$ (modelo Belga) sólo fue introducido en 1874. La Caballería usaba al comienzo de estas campañas, la pesada tercerola y el sable afilado a molejón. Pronto tuvo después la carabina Espencer y solo a principios de 1870, la carabina Winchester. La Artillería usaba el cañón de bronce francés, calibre cuatro y doce para los de montaña y campaña, aparte de los obuses 
de calibre doce y dieciséis libras, que por su menor peso y fácil atalaje a lomo de mula, eran los más usados en las campañas. También estaban en uso cañones de fierro de a 32 y otros calibres de los llamados de sitio y costa, que funcionaban sobre ejes giratorios en sólidas explanadas" (Navarro 2013:216 y 217). En el caso de la campaña de Villarrica se trasladó de una ametralladora Remington (Subercaseaux 2013:293), que posiblemente se comenzó a utilizar a partir del alzamiento general de 1881 .

17 Actual Cuerpo Militar del Trabajo.

18 En enero de 1871, antes de la creación de Zapadores, había 1.738 soldados trabajando en un canal de regadío cercano a Angol (ANH, MG 644, Angol, 13 febrero 1877, fs. sn.). Los vecinos de los poblados solicitaban y recibían el beneficio de este servicio gratuito (ANH, MG 1045, Angol, 26 abril 1883 , fs. $150-151$, vta.).
ANH, MG 1045, Angol, 1 mayo 1882, fs. 18, vta. 20 ANH, MG 1045, Cholchol, 1 agosto 1882, fs. 24, vta. 21 ANH, MG 1045, Angol, 18 abril 1884, fs. 270, vta. 22 ANH, MG 1045, Angol, 22 agosto 1883, fs.190, vta. 23 ANH, MG 602, Angol, 24 febrero 1869, fs. sn. 24 ANH, MG 486, Puerto Montt, 20 mayo 1881, fs. sn. 25 Ello se puede verificar en varios documentos: ANH MG 1045, Angol, 6 junio 1884, fs. 280-281; 536, Temuco, 21 junio 1887, fs. sn; Temuco, 5 julio 1887, fs. sn.

26 ANH, MG 1045, Angol, 18 noviembre 1882, fs. 61, vta. 27 ANH, MG 486, Angol, 19 diciembre 1880, fs. sn.; 536, Temuco, 16 junio 1887, fs. sn.

28 ANH, MG 644, Angol, 27 marzo 1872, fs. sn.

29 ANH, MG 1045, Angol, 19 febrero 1884, fs. 251, vta. 30 ANH, MG 536, Los Ángeles, 20 mayo 1867, fs. 466, 467. 
